\title{
Antifertility Effect of Inhaled Cannabis Sativa on Male Wistar Rats
}

\author{
Udokang Nsikak Ephraim, Udom Utibe Godwin
}

Department of Physiology, University of Uyo, Uyo, Nigeria

Email address:

nsikakudokang@yahoo.com (U. N. Ephraim)

\section{To cite this article:}

Udokang Nsikak Ephraim, Udom Utibe Godwin. Antifertility Effect of Inhaled Cannabis Sativa on Male Wistar Rats. American Journal of Health Research. Vol. 7, No. 2, 2019, pp. 1-7. doi: 10.11648/j.ajhr.20190701.11

Received: November 30, 2018; Accepted: December 29, 2018; Published: January 29, 2019

\begin{abstract}
A total of forty (40) male wistar rats randomly divided into four groups of ten (10) rats per group were used for this work. Group 1 served as the control and was treated with distilled water, group 2 was the low dose group (exposed to cannabis smoke for 5 minutes daily), group 3 was the high dose group (exposed to cannabis smoke for 10minutes daily) and group 4 was the high dose + ascorbic acid group (exposed to cannabis smoke for 10 minutes and orally gavaged with ascorbic acid at $2.8 \mathrm{mg} / \mathrm{kg}$ body weight daily). The rats were weighed weekly and the administration lasted for 28 days. The animals were sacrificed on the $29^{\text {th }}$ day and blood was collected by means of cardiac puncture. Serum was obtained for hormonal assay. The result showed a significant increase in the body weight ( $\mathrm{p}>0.05$ ) in the high dose group compared to low dose and high dose + ascorbic acid group, while the control group recorded the least body weight gained. There was significant decrease in testicular weight $(\mathrm{p}>0.05)$ in the experimental groups compared to the control group. Prolactin level was significantly increased $(p>0.05)$ in the high dose group compared to the other groups. Estradiol level was significantly decreased $(p>0.05)$ in the high dose group compared to the other groups. Testosterone level was significantly increased $(p>0.05)$ in the high dose + ascorbic acid group compared to the other groups. Follicle Stimulating Hormone (FSH) level was significantly increased $(\mathrm{p}>0.05)$ in the high dose and high dose + ascorbic acid group compared to the other two groups. Luteinizing Hormone (LH) level increased significantly $(p>0.05)$ in the control and high dose groups compared to the other two groups. From this result, it can therefore be concluded that cannabis sativa decreases testicular weight, estradiol and testosterone level and increases body weight, FSH, LH and prolactin level in male wistar rats. Also that ascorbic acid (vitamin c) was able to ameliorate some of these effects.
\end{abstract}

Keywords: Cannabis Sativa, Ascorbic Acid (Vitamin C), Antioxidant, Oxidative Stress, Antifertility

\section{Introduction}

Cannabis specifically refers to the green, brown, or gray mixture of dried, shredded leaves, stems, seeds, and flowers of the cannabis plant [1]. It is also called Marijuana. It is the most widely used illicit drug worldwide and became the second most commonly smoked substance after tobacco, with an estimated 160 million users $(3.8 \%$ of the world's population of 15-64 year olds) [2].

Though Cannabis is consumed by various routes, it is mostly smoked as cigarette [3]. While some people use it as an ingredient in foods, it has also been made available as beer.

Cannabis contains many chemicals, with $\Delta 9$ tetrahydrocannabinol $(\Delta 9-\mathrm{THC})$ and Cannabidiol (CBD) being the main ingredients of Cannabis sativa plant and having distinct symptomatic and behavioral effect [4].
Two cannabinoid receptor systems have been discovered, cannabinoid 1 receptor (CB1R) in the brain specific for $\Delta 9$ THC [5] and cannabinoid 2 receptor (CB2R) discovered by [6].

CB1Rs are mainly in the brain, particularly in the substantia nigra, the basal ganglia, limbic system, hippocampus and cerebellum, but are also expressed in the peripheral nervous system, liver, thyroid, uterus, bones and testicular tissue [7-9]. CB2Rs are mostly expressed in immune cells, spleen and the gastrointestinal system, and to some extent in the brain and peripheral nervous system $[9,10]$.

Studies have demonstrated that cannabis and its active component have widespread effects on multiple hormonal systems, including gonadal, adrenal, prolactin, growth hormone, and thyroid hormone regulation in experimental models [11].

Cannabis use is on the increase as many countries have 
decriminalized it. As such, interest has been drawn to the effects in which inhaled cannabis may have on the reproductive system.

The delay in conception as observed in couples in recent days compared to previous generation coincides with the increase use of cannabis [12]. Its use tends to be more prevalent among youths aged $<35$ years [13] and males appear to be more likely to use cannabis [14].

Following the above facts, it is of essence to investigate the harmful effects of cannabis as relates to fertility and to give an account of such with possible remedy.

\subsection{Purpose of the Study}

With the existence of cannaboid receptors in the brain and gonads, it is also likely that cannabis can alter the sex hormone levels because of its direct action on these organs which synthesize and regulate these hormones and possibly affect fertility. For this reason, this study soughts to investigate the;

i. Antifertility effect of inhaled cannabis on male wistar rats using body weight, testicular weight and sex hormone levels as the criteria.

ii. Potency of ascorbic acid in ameliorating the inhaled cannabis effects.

\subsection{Significance of the Study}

With increasing number of countries decriminalizing the use of cannabis, this study so to explore its antifertility effects, if any and the potency of ascorbic acid in reducing these effects.

\section{Methodology}

\subsection{Drugs and Animal Collection}

\subsubsection{Cannabis Sativa}

An approval and sample of cannabis sativa was gotten from The State Command, National Drug and Law Enforcement Agency (NDLEA), Akwa Ibom State Command, Uyo, for the study.

\subsubsection{Ascorbic Acid (Vitamin c)}

A packet of Emzor 100mg vitamin c tablets was bought from Leadsons pharmacy in Uyo, Akwa Ibom state.

\subsubsection{Animals}

Prepubertal rats of the Wistar strain (60-80g) were obtained from the animal house of the faculty of Basic Medical Sciences, University of Uyo and kept in wooden cages of $50 \times 30 \mathrm{~cm}$ dimension in a well-ventilated section of the same animal house for acclimatisation. The animals were fed with rat chow (vital feed) and were allowed free access to drinking water while the experiment lasted.

\subsection{Experimental Design}

A total of forty (40) prepubertal male albino rats were randomly designed into four (4) groups of ten (10) animals per group with group 1 as control group. Group 2, 3 and 4 served as experimental groups. Group 2 rats (low dose cannabis) were exposed to cannabis smoke through inhalation for 5 minutes a day. Group 3 rats (high dose cannabis) were exposed to cannabis smoke through inhalation for 10minutes a day. Group 4 (high dose cannabis + ascorbic acid) was exposed to cannabis smoke through inhalation for 10minutes a day and ascorbic acid. Group 1 (control group) were given distilled water and feed throughout the experimental days.

\subsection{Administration}

\subsubsection{Cannabis Sativa}

Daily, animals from group 2, 3 and 4 were exposed to cannabis smoke. This was done by putting $1 \mathrm{~g}$ of the cannabis rolled with rizla rolling paper in a red-hot charcoal in a stainless plate and placing it in an airtight smoking chamber with 10rats per smoking session for five (5) minutes. The procedure was repeated for the group 3 and 4 for another five (5) minutes each day, making the total time of exposure of this two groups (3 and 4) to be ten (10) minutes each day. The air-tight smoking chamber was made from polythene plastic cage of $60 \mathrm{~cm} \times 50 \mathrm{~cm} \times 40 \mathrm{~cm}$ dimension.

\subsubsection{Ascorbic Acid}

After the cannabis smoke exposure, the group 4 rats were orally gavaged with $2.8 \mathrm{mg} / \mathrm{kg}$ body weight of ascorbic acid.

\subsection{Sample Collection and Analysis}

\subsubsection{Sample Collection}

After 28 days of administration, the rats were anaesthetized using chloroform and sacrificed. Blood was collected by cardiac puncture into plain bottlesfor hormonal analysis. The testis was also collected and weighed. Approval was gotten from the Local Research Ethical Committee of the University of Uyo, Uyo, Akwa Ibom State, Nigeria.

\subsubsection{Determination of Hormonal Assay}

The collected blood was allowed to clot and centrifuged at 300 rev per minutes for 20 mins. The serum was collected with the aid of a micropipette and hormone levels determined by ELISA (Enzyme-linked immunosorbent assay) method using ELISA hormonal kits as follows:

\section{Prolactin}

i. All reagents, samples and calibrators were prepared;

ii. $25 \mu \mathrm{l}$ of each calibrator was pipetted into control and samples into the wells prepared.

iii. $50 \mu \mathrm{l}$ of Rat Prolactin Sample Buffer was added to every well.

iv. The mixture was shaken for 2 hours at room temperature $\left(18-28^{\circ} \mathrm{C}\right)$.

v. The content of the wells was discarded and the wells were washed 4 times with $300 \mu \mathrm{l}$ buffered wash solution. The microplate was beaten carefully to remove as much wash solution as possible.

vi. $200 \mu$ of Enzyme-Labeled Anti-Rat Prolactin Antibody was added to all wells.

vii. The mixture was shaken again for 1 hour. 
viii. The content of the wells were discarded and washed 4 times with $300 \mu \mathrm{l}$ buffered wash solution.

ix. The microplate was beaten carefully to remove as much wash solution as possible.

x. $200 \mu \mathrm{l}$ of liquid Substrate Solution was added to all wells.

xi. The solution was incubated without shaking for 30 minutes in the dark.

xii. $50 \mu$ l of Stop Solution was added to each well and mixed carefully.

xiii. The optical density at $450 \mathrm{~nm}$ was read. Bi-chromatic measurement with a reference at $600-690 \mathrm{~nm}$ was taken.

xiv. The developed color was stable for at least 30 minutes and optical densities were read during this time.

xv. A 4-Parameter-Fit with lin-log coordinates for optical density (linear scale) and concentration (logarithmic scale) was used to calculate the result.

\section{Testosterone and Estradiol}

i. All reagents, samples and calibrators were prepared.

ii. $100 \mu \mathrm{L}$ calibrator or sample was added to the appropriate well in the antibody pre-coated microtiter plate. $100 \mu \mathrm{L}$ of PBS ( $\mathrm{pH}$ 7.0-7.2) was added in the blank control well.

iii. And then conjugate was added immediately. It was shaken, mixed and incubated for 1 hour at $37^{\circ} \mathrm{C}$.

iv. It was aspirated and washed 5 times.

v. $50 \mu \mathrm{L}$ of substrate A and $50 \mu \mathrm{L}$ substrate B was added to each well including blank control well and incubated for $10-20$ minutes at $37^{\circ} \mathrm{C}$.

vi. $50 \mu \mathrm{L}$ Stop Solution was added to each well including blank control well and mixed well. vii. The optical density was read at $450 \mathrm{~nm}$ using a microplate reader immediately.

viii. A 4-Parameter-Fit with lin-log coordinates for optical density (linear scale) and concentration (logarithmic scale) was used to calculate the result.

III. FOLLICLE STIMULATING HORMONE (FSH) AND LUTEINIZING HORMONE (LH)

i. All reagents, samples and calibrators were prepared.

ii. $50 \mu \mathrm{L}$ calibrator or sample was added to each well. And then $50 \mu \mathrm{L}$ prepared Detection Reagent A was added immediately. It was shaken and mixed and incubated for 1 hour at $37^{\circ} \mathrm{C}$.

iii. It was aspirated and washed 3 times.

iv. $100 \mu \mathrm{L}$ prepared Detection Reagent B was added and incubated for 30 minutes at $37^{\circ} \mathrm{C}$.

v. It was aspirated and washed 5 times.

vi. $90 \mu \mathrm{L}$ Substrate Solution was added incubated for 1020 minutes at $37^{\circ} \mathrm{C}$.

vii. $50 \mu \mathrm{L}$ Stop Solution was added and read using a microplate reader at $450 \mathrm{~nm}$ immediately.

viii. Regression analysis was used to determine the result.

\subsubsection{Statistical Analysis}

Data obtained were analyzed using Mean, Standard Error of Mean and Analysis of Variance followed by Duncan's test which was used to determine the direction of significance. The level of weight and hormones were reported in the form mean \pm SEM and statistical significance was established at 0.05 level of significance with $\mathrm{p}<0.05$ signifying significance. Data were analyzed using the Statistical Package for Social Sciences (SPSS version 22.0) and GraphPad Prism 5.0.

\section{Results}

Table 1. Weight.

\begin{tabular}{lllll}
\hline Parameters & Group 1 (Control) & Group 2 (Low dose cannabis) & Group 3 (High dose cannabis) & $\begin{array}{l}\text { Group 4 (High dose cannabis }+ \\
\text { Ascorbic acid) }\end{array}$ \\
\hline Weight gained $(\mathrm{g})$ & $35.5018 .90^{\mathrm{a}}$ & $46.503 .44^{\mathrm{a}}$ & $53.173 .67^{\mathrm{b}}$ & $46.335 .38^{\mathrm{a}}$ \\
Testicular weight $(\mathrm{g})$ & $3.170 .19^{\mathrm{b}}$ & $2.540 .09^{\mathrm{b}}$ & $2.060 .12^{\mathrm{a}}$ & $1.905 .38^{\mathrm{a}}$ \\
\hline
\end{tabular}

Values reported in the form Mean \pm SEM. Similar superscript letters mean not significantly different ( $p>0.05$ ) while different superscript letters mean significantly different $(\mathrm{p}<0.05)$.

Result reveals that exposure to high dose of Cannabis caused a significant increase in weight than in groups exposed to low dose, high dose of Cannabis with ascorbic acid and the control group $(\mathrm{p}<0.05)$. There was a significant decrease in testicular weight in the group treated with high dose of Cannabis (group 2) and those treated with high of dose Cannabis combined with Ascorbic acid but between the control and the group exposed to low dose of Cannabis, there were no significant difference in their testicular weight $(\mathrm{p}>0.05)$ (Table 1).

Table 2. Hormonal Assay.

\begin{tabular}{lllll}
\hline Parameters & Group 1 (Control) & Group 2 (Low dose cannabis) & Group 3 (High dose cannabis) & $\begin{array}{l}\text { Group 4 (High dose cannabis + } \\
\text { Ascorbic acid) }\end{array}$ \\
\hline Prolactin $(\mathrm{ng} / \mathrm{ml})$ & $0.060 .002^{\mathrm{a}}$ & $0.060 .003^{\mathrm{a}}$ & $0.070 .001^{\mathrm{b}}$ & $0.050 .002^{\mathrm{a}}$ \\
Estradiol $(\mathrm{pg} / \mathrm{ml})$ & $2.150 .08^{\mathrm{b}}$ & $2.150 .09^{\mathrm{b}}$ & $1.850 .03^{\mathrm{a}}$ & $2.230 .05^{\mathrm{b}}$ \\
Testosterone $(\mathrm{ng} / \mathrm{ml})$ & $0.870 .15^{\mathrm{b}}$ & $0.230 .07^{\mathrm{a}}$ & $0.300 .04^{\mathrm{a}}$ & $1.130 .26^{\mathrm{c}}$ \\
FSH $(\mathrm{miu} / \mathrm{ml})$ & $0.040 .01^{\mathrm{a}}$ & $0.420 .07^{\mathrm{b}}$ & $0.470 .16^{\mathrm{b}}$ & $0.190 .05^{\mathrm{a}}$ \\
LH $(\mathrm{miu} / \mathrm{ml})$ & $2.500 .41^{\mathrm{b}}$ & $0.470 .16^{\mathrm{b}}$ & $2.880 .24^{\mathrm{b}}$ & $1.080 .07^{\mathrm{a}}$ \\
\hline
\end{tabular}

Values reported in the form Mean \pm SEM. Similar superscript letters mean not significantly different ( $p>0.05$ ) while different superscript letters mean significantly different $(\mathrm{p}<0.05)$. 
Result presented in Table 2 reveals that exposure to Cannabis caused a significant increase in Prolactin level, FSH and LH $(\mathrm{p}<0.05)$ but a significant decrease in Estradiol and Testosterone $(\mathrm{p}<0.05)$ in the group treated with high dose of Cannabis. In Group treated with combination of high dose of Cannabis and Ascorbic acid, there was a significant increase in testosterone only $(p<0.05)$ while for other hormones, an insignificant effect was established $(\mathrm{p}>0.05)$. Result also shows that exposure to low dose of Cannabis caused a significant increase in FSH and $\mathrm{LH}$ and a significant decrease in testosterone $(\mathrm{p}<0.05)$ but no effect on Prolactin and Estradiol ( $\mathrm{p}>0.05)$ (Table 2).

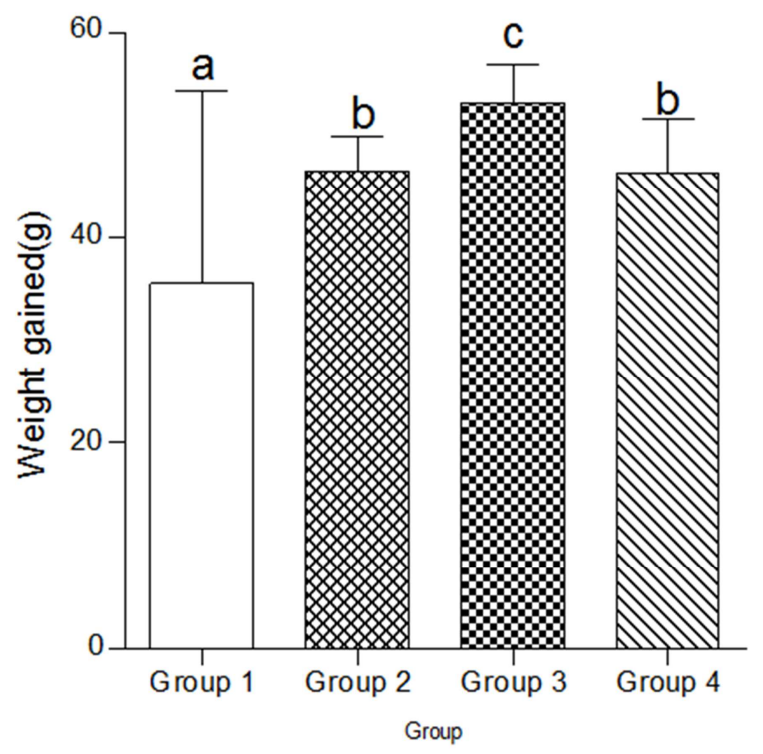

Figure 1. Graphical comparison of total body weight gained ( $g$ ) in the different experimental groups and the control group.

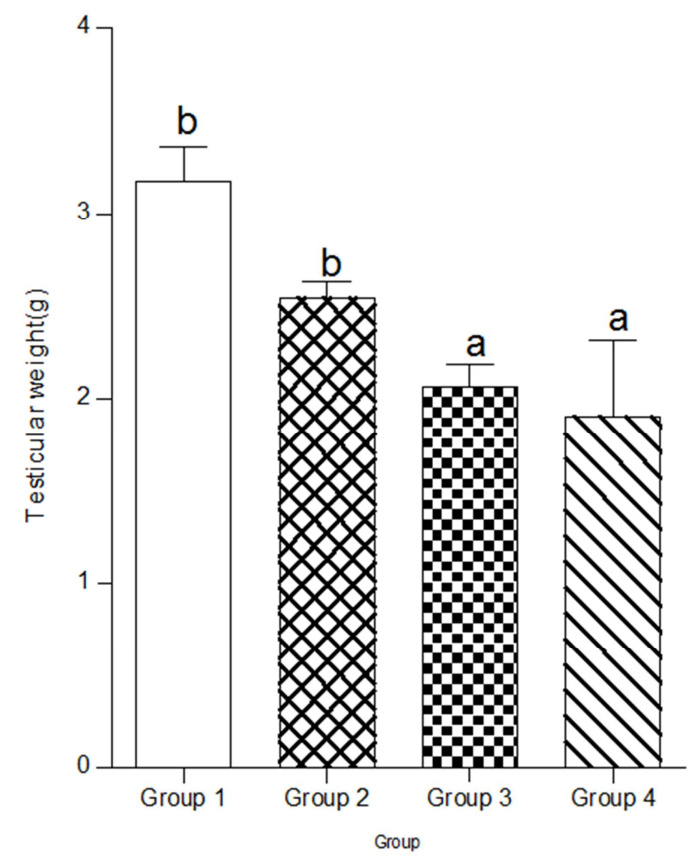

Figure 2. Graphical comparison of the testicular weight $(g)$ in the different experimental groups and the control group.

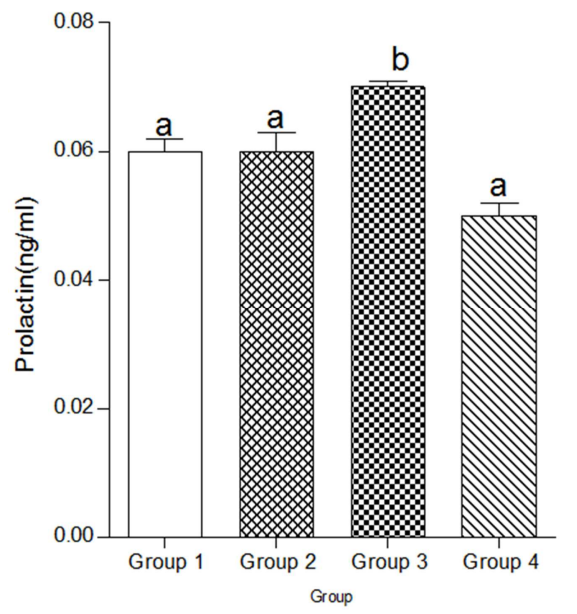

Figure 3. Comparison of prolactin levels $(\mathrm{ng} / \mathrm{ml})$ in the different experimental groups and the control group.

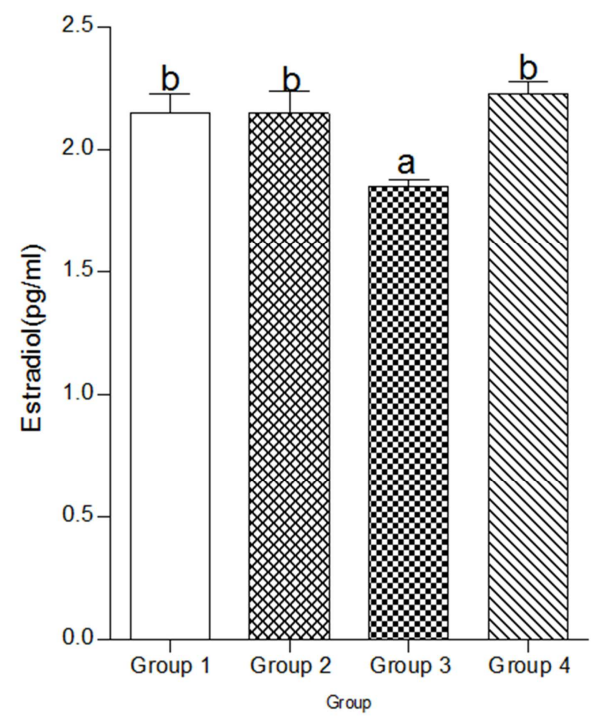

Figure 4. Graphical comparison of estradiol levels $(\mathrm{ng} / \mathrm{ml})$ in the different experimental groups and the control group.

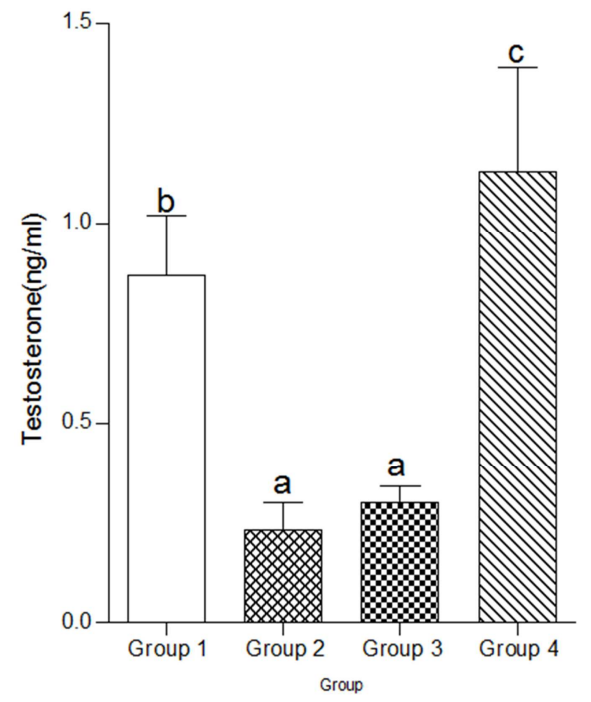

Figure 5. Graphical comparison of testosterone levels $(\mathrm{ng} / \mathrm{ml})$ in the different experimental groups and the control group. 


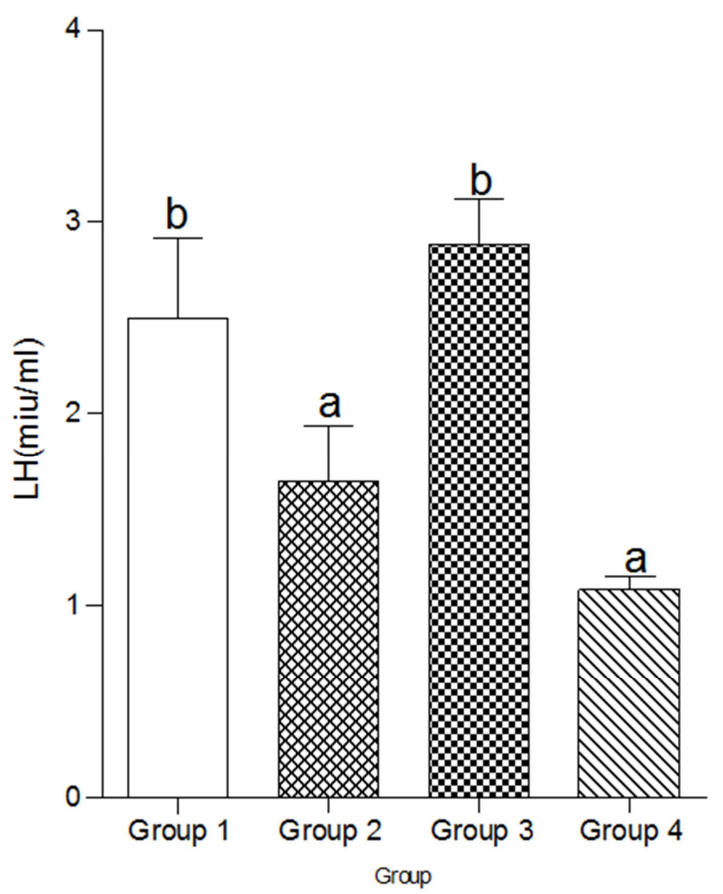

Figure 6. Graphical comparison of Luteinizing Hormone (LH) levels $(\mathrm{miu} / \mathrm{ml})$ in the different experimental groups and the control group.

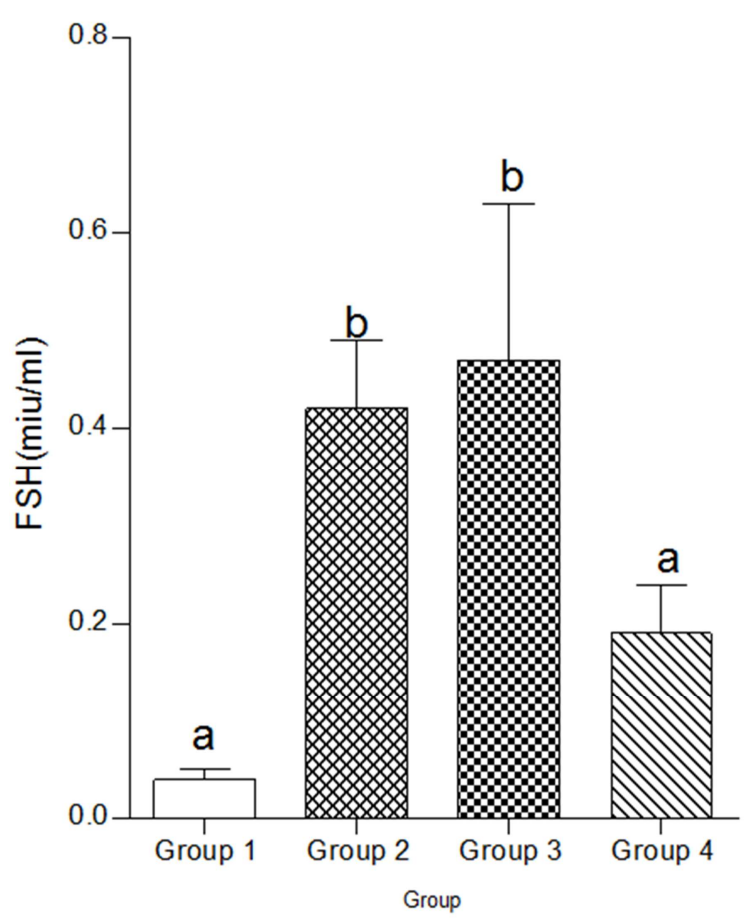

Figure 7. Graphical comparison of Follicle Stimulating Hormone (FSH) levels (miu/ml) in the different experimental groups and the control group.

\section{Discussion}

Inhaled cannabis interferes with normal body function as observed in the deviation of the tested parameters in the experimental groups from the control group. This deviation may be caused probably by the effects of intoxication by cannabis compounds; it can also be due to oxidative stressinduced damage since cannabis smoke generates free radicals (reactive oxygen species, ROS) which cause oxidative stress, [15]; or by the combined action of these two factors.

Reactive oxygen species (ROS) are reported to be tumorigenic [16] and can also induce cellular senescence and cell death [17]. According to [18] whether ROS causes tumor or apoptosis depends on the cell and tissues, the location of ROS production, and the concentration of individual ROS.

There are claims that cannabis and its chemical components appear to regulate feeding behavior. [19] state that the endocannabinoids are important biomediators and metabolic regulators in mammalian physiology, with diverse and ubiquitous modulating actions, including the regulation of body weight. Agonism of CB1 receptors is known to stimulate feeding behavior [20]. According to [21], stimulation of the CB1 receptors in the mammalian cannabinoid system specifically increases food cravings and promotes the deposition of energy as fat into adipose tissues. In this work, the increase in weight gained (figure 1) also support those claims, as such, we can say that cannabis smoke increases appetite and causes increase in body weight.

A number of animal studies have reported direct effects on various reproductive organs and this is observed in the reduction in testicular weight (figure 2) in this study. Hypogonadism was also reported by [22]. The decrease in testicular weight is an indication of the direct action of cannabis smoke on the testis inducing apoptosis through oxidative stress.

The hormonal assay of this work changes greatly among groups depending on the hormone (table 2). These changes have been observed to show a pattern, as pituitary gland hormone (prolactin, FSH and LH) levels increase while organ hormone (testosterone and estradiol) levels decrease.

The decrease in estradiol and testosterone levels (figure 4 and 5 respectively) is possibly supporting that fact that cannabis has direct effect on the testis as seen in the reduction in its weight. This effect has also been observed by many including [23], who proposed that chronic cannabis use reduces levels of circulating testosterone. The significant increase in the level of testosterone in the ascorbic acid group (figure 5) supports the finding by [24] that ascorbic acid increases testosterone levels, but the mechanism of its action is not well understood.

The effect of cannabis on prolactin secretion varies a great deal in different researches, though there are well documented evidences of cannabis causing increase in prolactin. One of the studies was by [25], who concluded that $\triangle 9$-THC causes increase in prolactin in male rats.

Although most studies show that cannabis reduces the level of $\mathrm{FSH}$, the result obtained in this work shows an increase in the levels of FSH (figure 7) and this is consistent with the other pituitary hormones (prolactin and LH) (figure 3 and 6). This may be due to a stimulating effect of inhaled cannabis smoke on the pituitary gland. Secondly, it may also be as a result of ROS-induced tumor in the pituitary gland caused by oxidative stress resulting in hypersecretion. Thirdly, it may be due to a feed-back effect of testosterone on 
the pituitary gland; this is specific in all the groups, as seen that the groups with low testosterone levels have increase LH levels and vice versa. The increased pituitary hormones secretion was unable to increase testosterone level since the leydig cells of the testis must have been severely destroyed by oxidative stress-induced apoptosis.

From the result obtained, ascorbic acid (an antioxidant) was observed to reduce the effect of cannabis in most of the measured parameters.

\section{Conclusion}

On the basis of this study, it can be postulated that inhalation of Cannabis sativa smoke can be anti-fertile probably due to its direct action on the testis and the pituitary gland. It causes decrease in testicular weight, testosterone and estradiol levels. It increases pituitary hormones possibly by the action on the pituitary gland in either of the following ways; direct stimulation, feedback mechanism from testosterone or by causing tumor growth resulting in hypersecretion.

It can also be assumed that cannabis smoke may be tumorigenic in the brain and apoptotic in other body organs.

Ascorbic acid (vitamin c) increases testosterone level and remedies the antifertility effects in male rats except in testicular weight in which the reduced weight was not ameliorated.

The antifertility effects of cannabis pose serious threat to the society. Consideringthe delay in conceptions in couples in recent days and the fact that many countries have decriminalized the use of cannabis, it can be suggested that in decades, the human race may be facing a very serious threat of extinction.

Therefore, it is necessary for the cultivation and use of this cannabis to be regulated by an authorised agency and researches on its effects be an area of interest to scientists.

\section{Acknowledgements}

We would like to appreciate the efforts of The State Commander, National Drug and Law Enforcement Agency (NDLEA), Akwa Ibom State Command for giving us the approval and sample of Cannabis sativa for this work.

\section{References}

[1] NIDA: National Institute on Drug Abuse, (2016). NIH. NIDA Info Facts: Marijuana NIDA publications. http://www.nida.nih.gov/infofacts/marijuana.html.

[2] UNODC: United Nations Office on Drugs and Crime Annual report 2008 (2008). Drugs, crime and terrorism cited from https://www.unodc.org/unode/en/data.

[3] Baggio, S., Deline, S., Studer, J., Mohler-Kuo, M., Daeppen, J. B. and Gmel, G. (2014). Routes of administration of cannabis used for nonmedical purposes and associations with patterns of drug use. Journal Adolescent Health. 54: 235-240.
[4] Bhattacharyya, S., Morrison, P.D., Fusar-Poli, P., MartinSantos, R., Borgwardt, S., Winton-Brown, T., Nosarti, C., O' Carroll, C.M., Seal, M., Allen, P., Mehta, M.A., Stone, J.M., Tunstall, N., Giampietro, V., Kapur, S., Murray, R.M., Zuardi, A.W., Crippa, J.A., Atakan, Z. and McGuire, P.K. (2010). Opposite effects of delta-9-tetrahydrocannabinol and cannabidiol on human brain function and psychopathology. Neuropsychopharmacology, 35 (3): 764-774.

[5] Devane, W., Dysarz, F., Johnson, M., Melvin, L. and Howlett, A. (1988) Determination and characterization of a cannabinoid receptor in rat brain. Molecular Pharmacology.34: 605-613.

[6] Munro, S., Thomas, K. and Abu-Shaar, M. (1993). Molecular characterization of a peripheral receptor for cannabinoids. Nature.365: 61-65.

[7] Russo, E. and Guy, G. (2006). A tale of two cannabinoids: the therapeutic rationale for combining tetrahydrocannabinol andcannabidiol. Medical Hypotheses. 66: 234-246.

[8] Pagotto, U., Marsicano, G., Cota, D., Lutz, B. and Pasquali, R. (2006). The emerging role of the endocannabinoid system in endocrine regulation and energy balance. Endocrine Reviews. 27: 73-100.

[9] Pertwee, R. (2006). The pharmacology of cannabinoid receptors and their ligands: an overview. International Journal of Obesity(London). 30: S13-S18.

[10] Izzo, A. (2004) Cannabinoids and intestinal motility: welcome to CB2 receptors. British Journal of Pharmacology. 142: $1201-1202$.

[11] Brown, T. T. and Dobs, A. S. (2002). Endocrine effects of marijuana. Journal of Clinical Pharmacology. 42(11 Supplement):90S-96S.

[12] Hsiao, P. and Clavijo, R. I. (2018). Adverse Effects of Cannabis on Male Reproduction. European UrologyFocus.

[13] World Drug Report 2017. https://www.unodc.org/wdr2017/index. html (accessed September 30, 2018).

[14] Johnston, L., O'Malley, P. M., Bachman, J. G. andSchulenberg, J. E. (2008). Monitoring the Future national surveyresults on drug use 1975-2007 Volume I: Secondary school students NIH publication no.08-6418A. Bethesda, Maryland: National Institute on Drug Abuse, U.S. Dept. of Health andHuman Services, National Institutes of Health.

[15] Hacışevki, A. (2009). An overview of ascorbic acid biochemistry. Journal of Faculty of Pharmacy. 38(3):233-255.

[16] Cerutti, P. A. (1985). Prooxidant states and tumor promotion. Science. 227: 375-381.

[17] DeMorrow, S., Francis, H., Gaudio, E., Ueno, Y., Venter, J., Onori, P. and Franchitto, A. (2008). Anandamideinhibits cholangiocyte hyperplastic proliferation via activation of thioredoxin 1/redox factor 1 andAP-1 activation. American Journal of Physiology- Gastrointestinal and Liver Physiology. 294:G506-519.

[18] Reuter, S., Gupta, S. C., Chaturvedi, M. M. and Aggarwal, B. B. (2010). Oxidative stress, inflammation, and cancer: How are they linked? Free Radical Biology and Medicine. 49(11): 1603-1616. 
[19] Vemuri, V. K., Janero, D. R. and Makriyannis, A. (2008). Pharmacotherapeutic targeting ofthe endocannabinoid signalingsystem: drugs for obesity and themetabolic syndrome. Physiology andBehaviour. 93:671-686.

[20] University of Washington. Marijuana. (2008). Sciencebasedinformation for the public.Locatedat:http://adai.washington.edu/marijuana/factshe ets/appetite.html.

[21] Kirkham, T. (2008). Endocannabinoids andthe neurochemistry of gluttony. Journal of Neuroendocrinology. 20: 1099-1100.

[22] Harclerode, J., Nyquist, S. E., Nazar, B. and Lowe, D. (1978). Effects of cannabison sex hormones and testicular enzymes of the rodent. Advances in Bioscience. 22-23:395-405.
[23] [Sugiura, T., Kondo, S., Sukagawa, A., Nakane, S., Shinoda, A., Itoh, K.,Yamashita, A. and Waku, K.(1995). 2Arachidonoylglycerol: a possibleendogenous cannabinoid receptor ligand in brain. Biochemical and BiophysicalResearch Communication.215:889-897.

[24] Okon, U. A. and Utuk, I. I. (2016). Ascorbic acid treatment elevates follicle stimulating hormone and testosterone plasma levels and enhances sperm quality in albino Wistar rats. Nigerian Medical Journal. 57(1): 31-36.

[25] Daley, J. D., Branda, L. A., Rosenfeld, J. and Younglai, E. V. (1974). Increase of serum prolactin in male rats by (-)-trans$\Delta$ 9-tetrahydrocannabinol. Journal of Endocrinology. 63:415416. 